\title{
Rapid Non-Destructive Testing Technique of Rockfill Dam Compactness Based on Surface Wave Method
}

\author{
Wan-Tang FEI ${ }^{1, a}$, Xue-Qing ZHANG ${ }^{2, b, *}$, Yu-Feng $\mathrm{MA}^{1, \mathrm{c}}$, Bin $\mathrm{LI}^{1, \mathrm{~d},{ }^{*}}$ and \\ Rui-Zeng ZHONG ${ }^{3, \mathrm{e}}$ \\ ${ }^{1}$ Hebei Fengning Pumped Storage Co.,Ltd,State Grid Xinyuan Company, Fengning, China \\ ${ }^{2}$ Henan Luoning Pumped Storage Co.,Ltd,State Grid Xinyuan Company Preparatory Office, Luoning, \\ China \\ ${ }^{3}$ Ningbo Hydraulic Waterpower Planning and Designing Research Institution \\ awantang-fei@sgxy.sgcc.com.cn, bxueqing-zhang@sgxy.sgcc.com.cn, \\ cyufeng-ma@sgxy.sgcc.com.cn, dbin-li.fn@sgxy.sgcc.com.cn, e 1227874761@qq.com
}

Keywords: Surface wave; non-destructive testing; Dry density.

\begin{abstract}
During the construction of rockfill dam, dry density is an important index of construction quality. Traditional dry density test pit sampling methods exist many drawbacks, such as time-consuming, laborious, the sampling rate is very low, representative data poor, etc. Surface waves non-destructive testing is a new method with high precision, simple, fast operation for detecting compacted rockfill dam dry density. This article made a further presentation on the principles of non-destructive testing surface wave method and its application examples in damming aspects.
\end{abstract}

SAW is a kind of non-destructive test method is based on the theory of surface wave, and is a new technology developed by modern electronic technology with high precision, simple, rapid detection, etc. It overcomes many shortcomings of traditional trenching sampling method[1-3].

\section{The Surface Wave Detection Principle}

Surface waves propagate only in the surface of the medium, but its propagation speed is comparable with underground construction has a close relationship, the "surface" is a certain thickness, and the thickness is related to the wavelength of surface wave, as shown in Figure 1. The amplitudes of surface waves fast decay from the medium surface along the depth direction, in less than half a wavelength of about more than $70 \%$ of the concentration of energy, and in less than one wavelength is concentrated all the energy above about $90 \%$. So the surface wave propagation velocity is mainly determined by the medium from the surface to a depth range of half a wavelength in the medium, and nearly independent outside of a wavelength medium. Obviously, the high frequency surface wave length is short, only through the medium and near the very shallow range of medium, so its propagation velocity reflects only superficial situation. But the low frequency surface wave with longer wavelengths can penetrate from the surface to the depths of the medium, so it can reflect the propagation velocity from the surface to the deep influence of the medium. If we can get from high to low frequency of Rayleigh wave propagation velocity, we can get the information reflecting the media, with mathematical method according to a depth of the separate this information, we can grasp the whole medium internal structure, which is of surface wave method principle.

\section{Test Methods}

In order to combine the results of the field test by irrigation of dry density, before irrigation method test performed to detect surface waves selected test positions, as shown in Figure 2, which is to ensure irrigation method test and surface wave test position is consistent. 


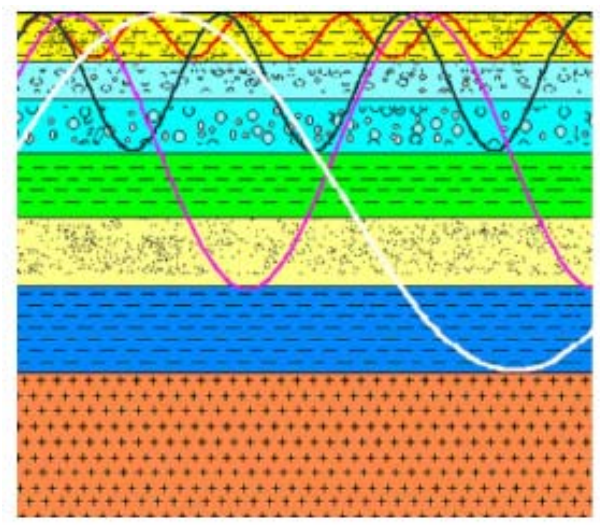

Figure 1 Schematic diagram of the surface wave exploration principle

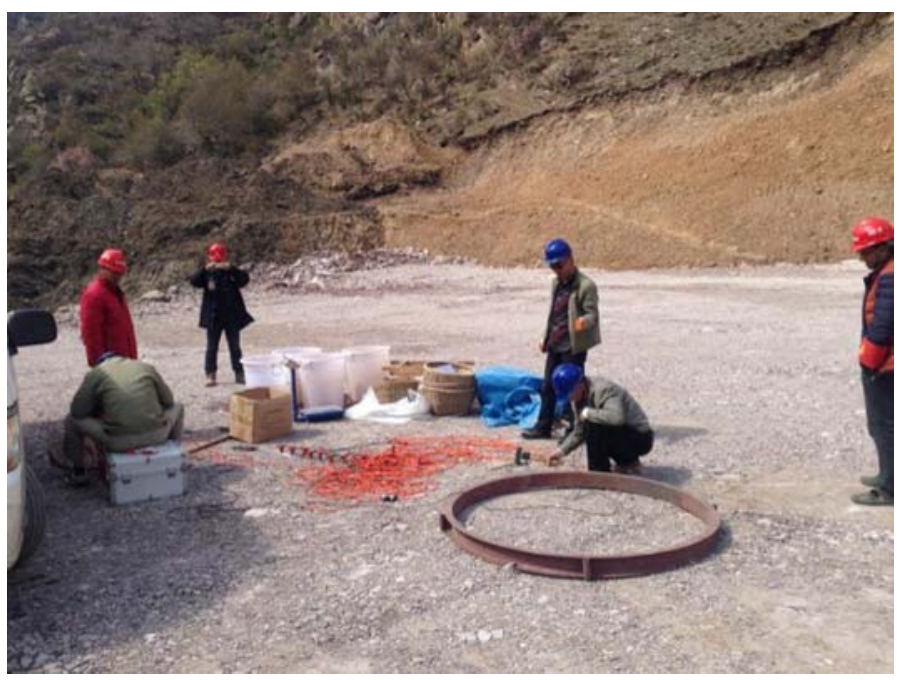

Figure 2 The surface wave detection position selection

Velocity measurement area arranged two orthogonal survey lines. According to different packing, through the test to determine the optimal spacing and offset, main rockfills spacing $10 \mathrm{~cm} \sim 20 \mathrm{~cm}$, offset $100 \sim 200 \mathrm{~cm}$. Considering the cushion material and excessive material laying depth is small, select the track pitch and the offset distance appropriate to reduce, the specific arrangement as shown in Figure 3.

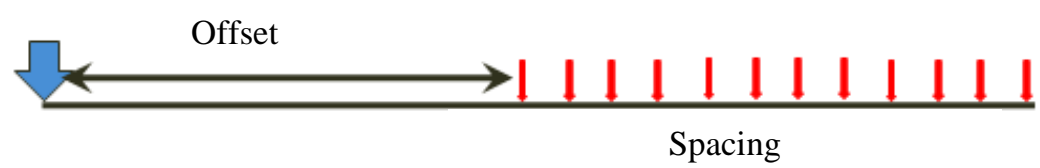

Figure 3 The exciter and detector arrangement

\section{The Detection Result}

To deal with the collected wave, the irrigation method test of dry density values were fitted with wave velocity test results, the fitting curve as shown in Figure 4. Linear fitting results are shown in Formula 1 , its basic meaning is: the minimum dry density test $1.956 \mathrm{~g} / \mathrm{cm} 3$, with the increase of the testing velocity, the dry density increased linearly. After fitting curve generated, you can use the curve to achieve rapid detection, using surface wave method to measure velocity directly in the fitting curve check corresponding density. 


$$
\rho_{\mathrm{d}}=0.001539 \times V_{\mathrm{R}}+1.956
$$

$\rho_{\mathrm{d}} \_$dry density;

$V_{\mathrm{R}}$ — surface wave velocity.

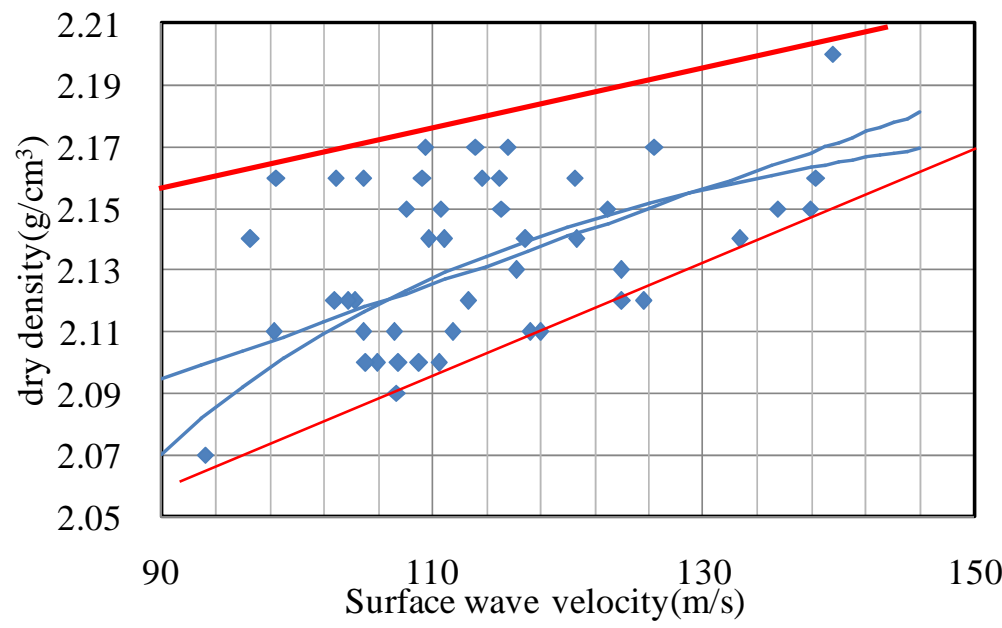

Figure 4 The fitting curve

The fitting errors are shown in table 1 :

Table 1 Fitting error range

\begin{tabular}{|c|c|c|c|c|}
\hline $\begin{array}{c}\text { the maximum } \\
\text { surface wave } \\
\text { velocity }(\mathrm{m} / \mathrm{s})\end{array}$ & $\begin{array}{c}\text { the minimum } \\
\text { value of surface } \\
\text { wave velocity } \\
(\mathrm{m} / \mathrm{s})\end{array}$ & $\begin{array}{c}\text { the measured } \\
\text { maximum dry density } \\
\left(\mathrm{g} / \mathrm{cm}^{3}\right)\end{array}$ & $\begin{array}{c}\text { the measured } \\
\text { minimum dry density } \\
\left(\mathrm{g} / \mathrm{cm}^{3}\right)\end{array}$ & $\begin{array}{c}\text { The maximum } \\
\text { fitting error }(\%)\end{array}$ \\
\hline 139.5 & 93.3 & 2.20 & 2.07 & 3.4 \\
\hline
\end{tabular}

\section{Conclusion}

Field application proves that surface wave velocity method to detect main rockfill material dry density and has the advantages of fast testing speed, high precision, installation is simple, intelligent instrument, automation, field staff easy to master the operation etc., and instrument for small portable, seal structure, battery powered, to adapt to the construction site work conditions, the new technology can be in hydropower dam engineering widely.

\section{References}

[1] Rayleigh L. On waves propagated along the plane surface of an elastic solid[J].Proceedings of the London Mathematical Society, 1885,1(1):4-11.

[2] Thomson,W.T. Transmission of elastic waves through a stratified solid medium[J].Journal of Applied Physics.1950,21(2):89-93.

[3] Thrower E.N. The computation of the dispersion of elastic waves in layered media [J].Journal of Sound and Vibration. 1965, 2(3): 210-226. 